\title{
Role of acetylcholine and calcium ions in three vascular contraction models: Angiotensin II, phenylephrine and caffeine
}

\author{
KATARZYNA SZADUJKIS-SZADURSKA, GRZEGORZ GRZESK, LESZEK SZADUJKIS-SZADURSKI, \\ MARTA GAJDUS and GRZEGORZ MATUSIAK
}

Department of Pharmacology and Therapeutics, Collegium Medicum

Nicolaus Copernicus University, 85-094 Bydgoszcz, Poland

Received February 26, 2012; Accepted April 13, 2012

DOI: $10.3892 /$ etm.2012.573

\begin{abstract}
The aim of this study was to determine the role of acetylcholine and calcium ions in modulating the vascular contraction induced by angiotensin II (ANG II), phenylephrine (PHE) and caffeine. The study was performed on perfunded Wistar rat tail arteries. The contraction caused by ANG II, PHE and caffeine with the participation of intracellular [in free physiological salt solution (FPSS)] and extracellular [in physiological salt solution (PSS), after emptying the cellular stores] pools of calcium ions and the addition of L-NNA (NOSe inhibitor) or ODQ (GC inhibitor) was studied. Then the effect of acetylcholine on the contraction responses was analyzed. ANG II, PHE and caffeine induced an increase in perfusion pressure in PSS and FPSS. Acetylcholine reduced the contraction resulting from the presence of ANG II and PHE, but not caffeine. L-NNA and ODQ abolished the spasmolytic action of acetylcholine. Both pools of calcium ions mediated the action of ANG II and PHE, and caffeine induced the contraction with the participation of calcium released from intracellular stores. The spasmolytic effect of acetylcholine on responses stimulated by ANG II and PHE indicates the participation of nitric oxide in modulating the reactivity of the arteries on the studied agonists of the metabotropic receptors. No observed acetylcholine effect on caffeine suggests that the pathway associated with nitric oxide does not interfere with the contraction induced by the ryanodin receptor.
\end{abstract}

\section{Introduction}

The reactivity of blood vessels depends on their structure and the presence of calcium ions (1). It is modulated by numerous factors, which activate specific signaling pathways leading to contraction or relaxation of smooth muscle. The action of

Correspondence to: Dr Katarzyna Szadujkis-Szadurska, Department of Pharmacology and Therapeutics, Collegium Medicum Nicolaus Copernicus University, Skłodowskiej-Curie Street 9, 85-094 Bydgoszcz, Poland

E-mail: kataszsz@gmail.com

Key words: angiotensin II, phenylephrine, caffeine, contraction, acetylocholine, calcium ions various vasodilatation substances may be altered under the influence of similar or quite different modulators. Vascular reactivity may vary with age, which probably is associated with endothelial dysfunction, leading to a reduction in nitric oxide synthesis (2-4). Angiotensin II (ANG II) triggers vasoconstriction via a metabotropic AT1 receptor (5). ANG II also regulates smooth muscle cell (SMC) growth, has an effect on apoptosis and migration and has proinflammatory action. In addition, it causes the production of other growth- and contraction-stimulating factors. It is, therefore, important both for maintaining the proper structure and function of blood vessels and may mediate pathophysiological processes leading to the development of cardiovascular diseases (6). Phenylephrine (PHE) is an agonist of the $\alpha 1$-adrenergic metabotropic receptor through which it induces vasoconstriction (7).

Both substances, ANG II and PHE, act through G proteins, which leads to stimulation of phospholipase $C$ and the synthesis of secondary messengers: $\mathrm{IP}_{3}$ and DAG (8-10). $\mathrm{IP}_{3}$ binds to the endoplasmic reticulum membrane $(\mathrm{ER}) \mathrm{IP}_{3} \mathrm{R}$ receptors and causes the release of $\mathrm{Ca}^{2+}$ from intracellular pools. The ryanodin receptors (RyR), stimulated, among others, by caffeine $(1,11,12)$ are an alternative way for the release of calcium from the ER. Contraction of vascular smooth muscle may also occur via calcium ions escaping from the extracellular space through channels in the cell membrane [receptor-operated $\mathrm{Ca}^{2+}$ channels (ROC)] activated by ligand ANG II or PHE (13).

Studies on vas deferens (human and rat) and rat tail artery have shown that receptor associated G-protein modulation may be influenced by sodium nitroprusside and $8 \mathrm{Br}-\mathrm{cGMP}$ (14-16). Nitric oxide derived from endothelium is a major vasodilatation factor (17). Acetylcholine can stimulate the release of nitric oxide in a cGMP-mediated relaxing effect $(18,19)$. However, studies using isolated human placental villous arteries found that NO donors and 8Br-cGMP did not cause relaxation of arteries contracted with caffeine. The mechanism of nitric oxide action on the cardiac calcium release channel (ryanodine receptor) (CRC) in canines was explored $(20,21)$. Lim et al discussed various ways in which nitric oxide can modulate cardiac ryanodine receptor function and suggested the possibility of pharmacological strategies in heart failure, related to the considered mechanisms (22).

The aim of this study was to assess the role of acetylcholine and calcium ions in modulating the contraction induced by 


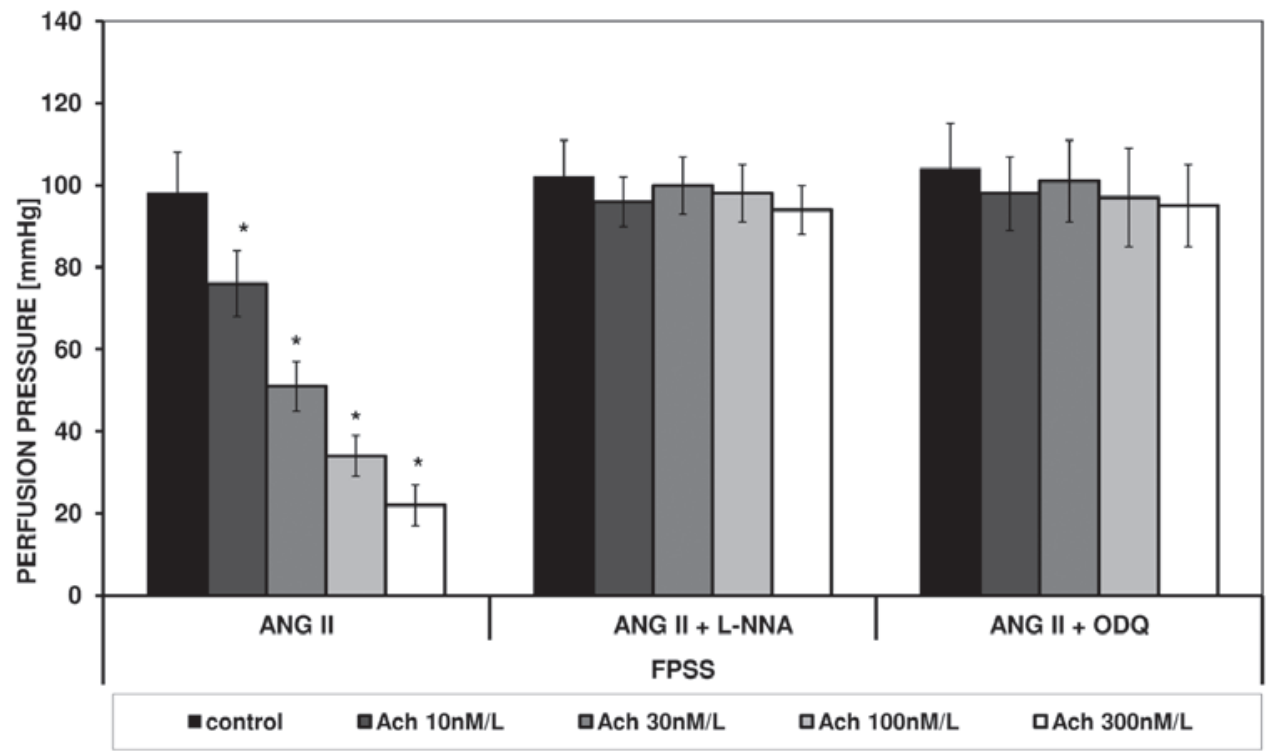

Figure 1. Influence of acetylcholine (Ach) on the vascular contraction induced by ANG II in FPSS, in the presence of L-NNA (10 $\mu \mathrm{M} / \mathrm{l})$ and ODQ (10 $\mu \mathrm{M} / 1)$; (mean $\pm \mathrm{SE}, \mathrm{n}=12$ ); ${ }^{*} \mathrm{p}<0.0001$ vs. control. FPSS, free physiological salt solution.

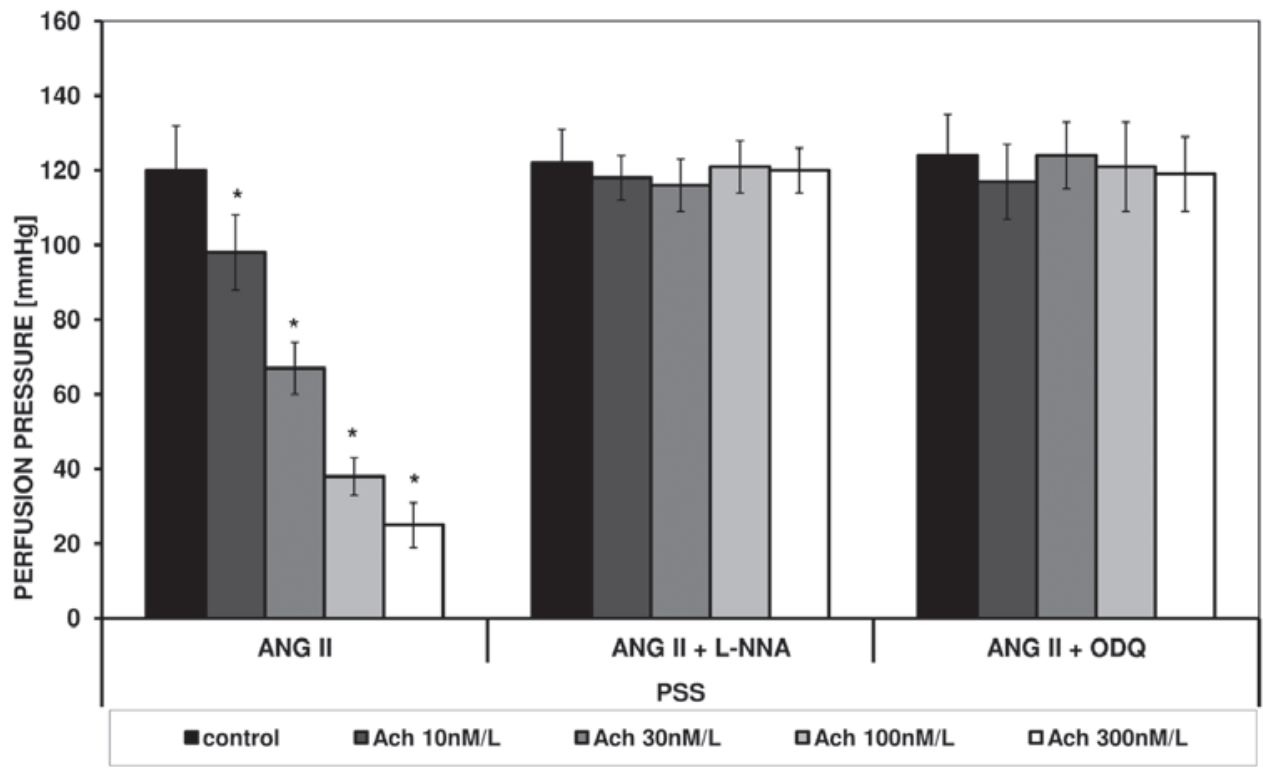

Figure 2. Influence of acetylcholine (Ach) on the vascular contraction induced by ANG II in PSS, in the presence of L-NNA (10 $\mu \mathrm{M} / \mathrm{l})$ and ODQ (10 $\mu \mathrm{M} / \mathrm{l})$; (mean $\pm \mathrm{SE}, \mathrm{n}=12$ ); ${ }^{*} \mathrm{p}<0.0001$ vs. control. PSS, physiological salt solution.

ANG II, PHE and caffeine. These substances acted together with the participation of calcium ions mobilized from intracellular stores, but also (as in the case of ANG II and PHE) using an extracellular pool of these ions.

\section{Materials and methods}

The study was performed on perfunded tail arteries of male Wistar weighing 250-350 g, euthanized with an intraperitoneally injection of urethane at the dose of $120 \mathrm{mg} / \mathrm{kg}$. The cannula was introduced in the proximal section of rat tail artery (2.5-3 cm in length) and combined with a perfusion system and a set that allows constant measurement and recording of perfusion pressure. After loading the distal end of the isolated artery with a weight of $500 \mathrm{mg}$, the preparation was placed upright in a thermostated vessel for isolated organs $20 \mathrm{ml}$ in volume and oxygenated with physiological fluid at a temperature of $37^{\circ} \mathrm{C}$. Perfusion fluid flow was increased gradually to $1 \mathrm{ml} / \mathrm{min}$.

The experiments were carried out to determine the importance of intracellular and extracellular pools of $\mathrm{Ca}^{2+}$ in reactions induced by ANG II (30 nM/l), PHE (3 $\mu \mathrm{M} / \mathrm{l})$ and caffeine $(100 \mu \mathrm{M} / \mathrm{l})$ in control conditions and after addition of L-NNA (NOSe inhibitor) or ODQ (a soluble form of GC inhibitor) and in the presence of increasing concentrations of acetylcholine using two types of Krebs fluid: i) FPSS - $\mathrm{Ca}^{2+}$-free EGTA- 


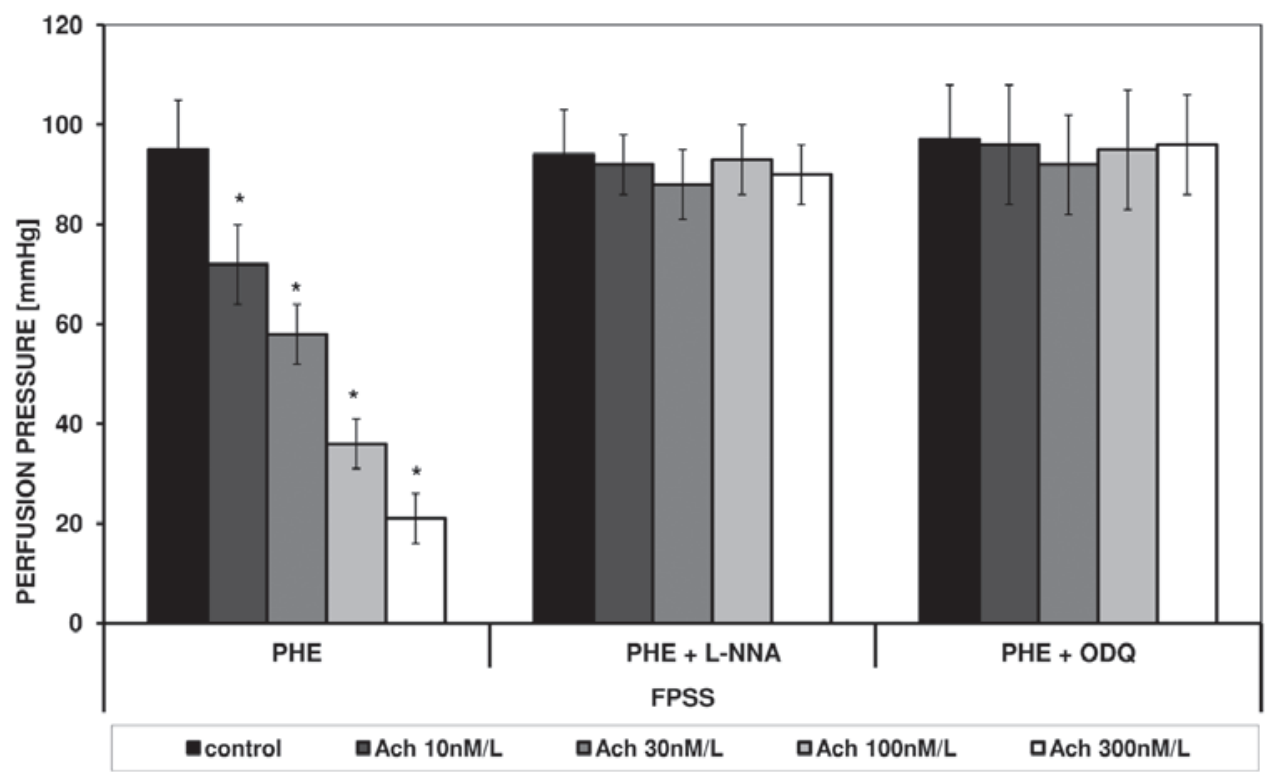

Figure 3. Influence of acetylcholine (Ach) on the vascular contraction induced by PHE in FPSS, in the presence of L-NNA (10 $\mu \mathrm{M} / 1)$ and ODQ (10 $\mu \mathrm{M} / 1)$; (mean $\pm \mathrm{SE}, \mathrm{n}=12$ ); " $\mathrm{p}<0.0001$ vs. control. PHE, phenylephrine; FPSS, free physiological salt solution.

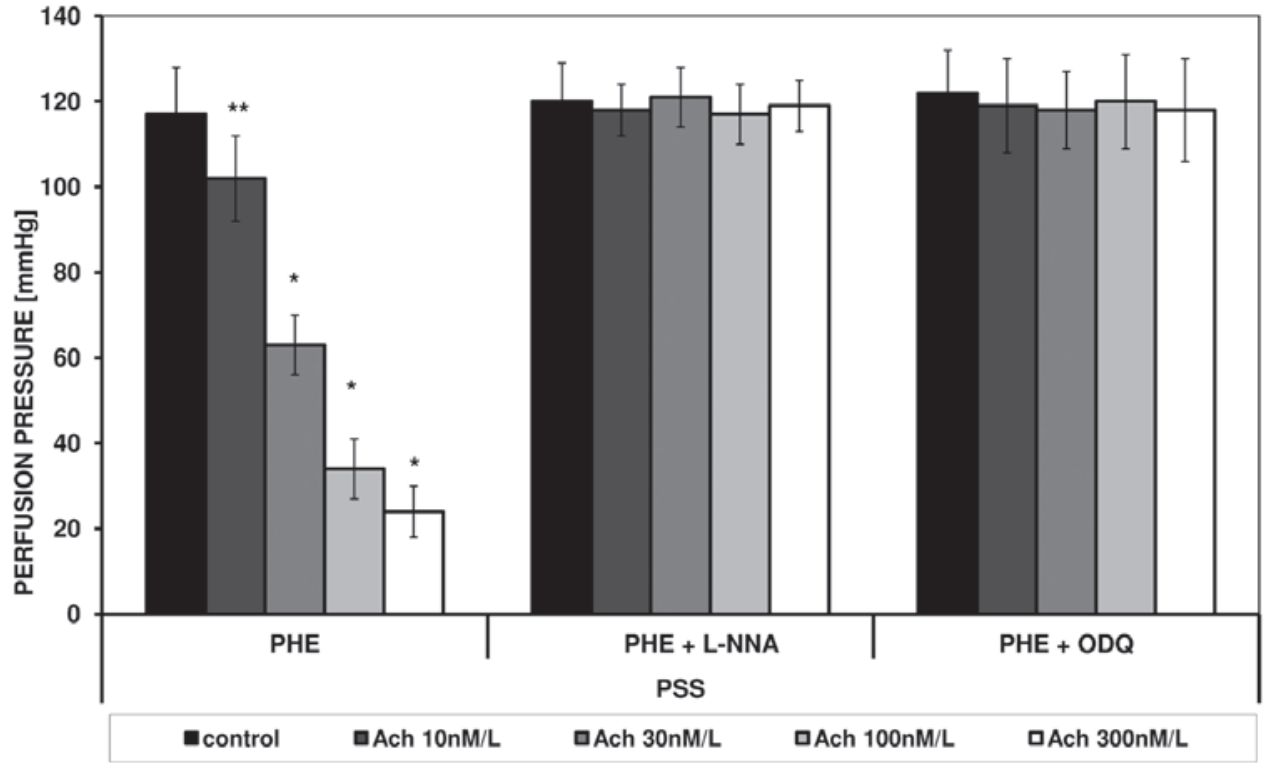

Figure 4. Influence of acetylcholine (Ach) on the vascular contraction induced by PHE in PSS, in the presence of L-NNA (10 $\mu \mathrm{M} / 1)$ and ODQ (10 $\mu \mathrm{M} / 1)$; (mean $\pm \mathrm{SE}, \mathrm{n}=12) ;{ }^{*} \mathrm{p}<0.0001$ vs. control; ${ }^{* *} 0.05>\mathrm{p}>0.0001$ vs. control. PHE, phenylephrine; PSS, physiological salt solution.

Krebs with the following composition: $\mathrm{NaCl}(71.8 \mathrm{mM} / \mathrm{l}), \mathrm{KCl}$ (4.7 mM/l), $\mathrm{NaHCO}_{3}(28.4 \mathrm{mM} / \mathrm{l}), \mathrm{MgSO}_{4}(2.4 \mathrm{mM} / \mathrm{l}), \mathrm{KH}_{2} \mathrm{PO}_{4}$ $(1.2 \mathrm{mM} / \mathrm{l})$, glucose $(11.1 \mathrm{mM} / \mathrm{l})$ with the addition of EGTA (30 $\mu \mathrm{M} / \mathrm{l})$; ii) PSS - fluid with $\mathrm{Ca}^{2+}$ EGTA-Krebs (normal) with the following composition: $\mathrm{NaCl}(71.8 \mathrm{mM} / \mathrm{l}), \mathrm{KCl}(4.7 \mathrm{mM} / \mathrm{l})$, $\mathrm{CaCl}_{2}(1.7 \mathrm{mM} / \mathrm{l}), \mathrm{NaHCO}_{3}(28.4 \mathrm{mM} / \mathrm{l}), \mathrm{MgSO}_{4}(2.4 \mathrm{mM} / \mathrm{l})$, $\mathrm{KH}_{2} \mathrm{PO}_{4}(1.2 \mathrm{mM} / \mathrm{l})$, glucose $(11.1 \mathrm{mM} / \mathrm{l})$ with addition of EGTA (30 $\mu \mathrm{M} / \mathrm{l})$, after emptying the intracellular pool of calcium ions.

The increase in pressure of the perfusate in the experimental system was an exponent of vessel spasm. The Ethical Committee for the Affairs of Experiments on Animals in Bydgoszcz approved the protocol of the experiments undertaken (No. 1/2008-4).
Statistical analysis was performed by determining the mean and standard deviation. Statistical differences were evaluated by Student's t-test. A p-value $<0.05$ was considered to indicate a statistically significant difference.

\section{Results}

ANG II caused an increase in perfusion pressure in FPSS and PSS. Under the influence of increasing concentrations of acetylcholine a statistically significant reduction in perfusion pressure in both types of fluid was noted (Figs. 1 and 2).

In the presence of L-NNA and ODQ in both solutions no changes in contraction stimulated by ANG II or spasmolytic 


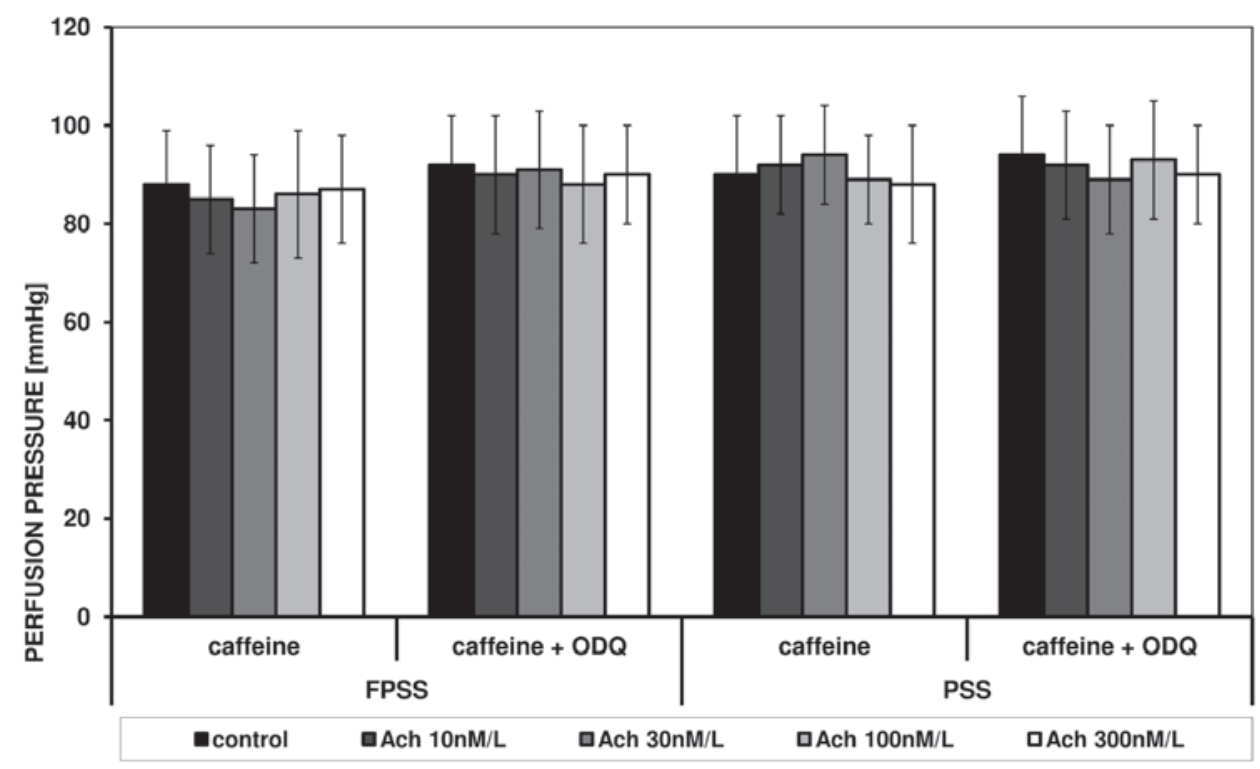

Figure 5. Influence of acetylcholine (Ach) on the vascular contraction induced by caffeine in PSS and FPSS, in the presence of ODQ (10 $\mu \mathrm{M} / \mathrm{l})$; (mean \pm SE, $\mathrm{n}=12$ ). PSS, physiological salt solution; FPSS, free physiological salt solution.

effect of acetylcholine were observed (Figs. 1 and 2). PHE, in a similar manner to ANG II caused contraction in FPSS and PSS, which was similarly modulated by acetylcholine. Figs. 3 and 4 present the effect of increasing concentrations of acetylcholine on the perfusion pressure induced by PHE in the presence of L-NNA and ODQ, respectively, in FPSS and PSS.

Caffeine induced an increase in perfusion pressure in FPSS and PSS, and these reactions were not altered under the influence of acetylcholine and ODQ. Fig. 5 shows the effect of increasing concentrations of acetylcholine on caffeinetriggered contraction in the presence of ODQ, FPSS and PSS.

\section{Discussion}

Calcium ions are an essential element in muscle contraction. Vascular tone can be adjusted by a variety of substances that stimulate the release of calcium from cellular stores, that cause the influx of calcium from the outside, and that stimulate sensitivity to calcium ions. A key role in regulating muscle function is maintaining the concentration of calcium ions within a very narrow range and regulating their ability for rapid increase (1). An increase in intracellular calcium levels precedes and induces the contraction of smooth muscle. Acetylocholine decreases arterial tension due to the release of NO from endothelial cells, thus it stimulates the NO/cGMP signaling pathway (23). Cyclic nucleotides, e.g., cAMP and cGMP, which regulate the function of ion channels and calcium levels in the cell through the appropriate protein kinases exhibit functional antagonism of calcium ions in smooth muscle $(24,25)$. In experiments performed on mouse lung slices NO-induced relaxation was enhanced by selective inhibitors of cGMP-specific phosphodiesterase-5 (zaprinast or vardenafil), but was blocked by ODQ and by Rp-8pCPT-cGMPS, an inhibitor of protein kinase G. NOC-5 (nitric oxide donor), cGMP analogues and selective PKG activators $8 \mathrm{Br}-\mathrm{cGMP}$ and $8 \mathrm{pCPT}-\mathrm{cGMP}$ were found to induce airway relaxation and decrease the frequency of $\mathrm{Ca}^{2+}$ oscillations (26). Studies using human mesenteric arteries showed that guanylate cyclase activators modulate vascular responses in conditions of ischemia/reperfusion (27). The aim of the present study was to determine the role of acetylcholine and calcium ions in modulating the vascular contraction induced by angiotensin II, phenylephrine and caffeine.

The experiments were carried out in PSS (after emptying the intracellular pool of calcium ions) and FPSS to determine the importance of the extracellular and the intracellular pools of calcium ions. Metabotropic receptor agonists, ANG II and PHE, led to an increase in perfusion pressure in both types of solutions; the reactions were stronger in PSS. Comparison of the results indicates that the vascular contraction induced by the studied substances was caused by the effect of calcium ions released from the endoplasmic reticulum (via the $\mathrm{IP}_{3}$ receptor), entering the cell from the outside after opening the appropriate channels in the membrane. Similar observations were also derived from experiments on rat aorta and human mesenteric arteries $(28,29)$.

The existence of a contraction mechanism independent of the intracellular calcium pool confirms previous experience using rat tail artery and human mesenteric arteries with xestospongin $\mathrm{C}$, an $\mathrm{IP}_{3}$ receptor antagonist $(29,30)$. Acetylcholine reduced the vascular contraction stimulated by ANG II and PHE in a concentration-dependent manner. Additionally, in experiments using human mesenteric arteries such an effect of acetylcholine was observed (18). Ji et al in studies of rat aorta demonstrated that the inhibitory effect of acetylcholine was associated with the presence of endothelial cells and this effect was not present in experiments carried out in arteries denuded of endothelium (27). Another series of studies found that blocking NO synthase (after addition of L-NNA) and soluble guanyl cyclase (GC, after addition of ODQ) led to the elimination of the relaxing effects of acetylcholine. These results confirm the dependence of acetylcholine on NO synthesis and activation of GC.

A subsequent experiment was performed in FPSS and PSS using caffeine, agonist of ryanodin receptors in the endoplasmic reticulum, as a factor stimulating vascular contraction. Previous studies in human mesenteric arteries showed that 
emptying the intracellular pool of $\mathrm{Ca}^{2+}$ and blockage of $\mathrm{Ca}^{2+}$ ATPase (by specifying thapsigargin) caused the abolition of the response to caffeine (29). In contrast to the results of the metabotropic receptor agonists, acetylcholine did not inhibit caffeine-triggered contraction. This effect was consistent with previous reports $(28,29)$. It was previously shown that the NPS, as a donor of $\mathrm{NO}$, decreased rat artery contraction, induced by ANG II and PHE, but was not affected by caffeine (27). The effect of $\mathrm{NO}$ on $\mathrm{Ca}^{2+}$ sensitivity of airway SMCs was examined in mouse lung slices permeabilized to $\mathrm{Ca}^{2+}$ by treatment with caffeine and ryanodine. Neither NOC-5 nor 8pCPT-cGMP induced relaxation in agonist-contracted $\mathrm{Ca}^{2+}$-permeabilized airways (26). Slupski et al showed that nitric oxide may reduce lung damage caused by increased vascular resistance and arterial pressure after ischemia/reperfusion (30).

In the present study the importance of calcium ions and acetylcholine, as an element in the Ach/NO/cGMP signaling pathway in the vascular contraction induced by ANG II and PHE through metabotropic receptors (AT1 and $\alpha 1$-adrenergic, respectively) was compared with the action of caffeine, a ryanodin receptor agonist, in ER. Ji et al explained that the lack of impact of acetylcholine and sodium nitroprusside on contraction caused by caffeine is likely due to the fact that NO can selectively block the release of calcium ions from the ER through an $\mathrm{IP}_{3}$-dependent pathway (27). Perez-Zoghbi et al concluded that NO, acting via the cGMP-PKG pathway, induced airway SMC relaxation by predominately inhibiting the release of $\mathrm{Ca}^{2+}$ via the $\mathrm{IP}_{3}$ receptor to decrease the frequency of agonist-induced $\mathrm{Ca}^{2+}$ oscillations (26).

The action of ANG II and PHE was mediated by two pools of calcium, and caffeine induced the contraction with the participation of calcium released from intracellular stores. The relaxing effect of acetylcholine on responses stimulated by ANG II and PHE indicates the participation of nitric oxide in modulating the reactivity of arteries to the studied metabotropic receptor agonists. No effect of acetylcholine on caffeine action suggests that the pathway associated with nitric oxide does not interfere with the vascular contraction induced by the ryanodin receptor.

\section{References}

1. Karaki H, Ozaki H, Hori M, et al: Calcium movements, distribution, and functions in smooth muscle. Pharmacol Rev 49: 157-230, 1997.

2. Stewart K, Zhang $\mathrm{Y}$ and Davidge ST: Aging increases PGHS-2-dependent vasoconstriction in rat mesenteric arteries. Hypertension 35: 1242-1247, 2000.

3. Barton M, Cosentino F, Brandes RF, Moreau P, Shaw S and Lüscher TF: Anatomic heterogeneity of vascular aging: role of nitric oxide and endothelin. Hypertension 30: 817-824, 1997.

4. Cernadas MR, Sanchez de Miguel L and Garcia-Duran M: Expression of constitutive and inducible nitric oxide synthases in the vascular wall of young and aging rats. Circ Res 83: 279-286, 1998.

5. Gasparo M, Catt KJ, Inagami T, Wright JW and Unger TH: International union of pharmacology. XXIII. The angiotensin II receptors. Pharmacol Rev 52: 415-472, 2000.

6. Mehta PK and Griendling KK: Angiotensin II cell signaling: physiological and pathological effects in the cardiovascular system. Am J Physiol Cell Physiol 292: C82-C97, 2007.

7. Seasholtz TM, Gurdal H, Wang HY, Cai G, Johnson MD and Friedman E: Heterologous desensitization of the rat tail artery contraction and inositol phosphate accumulation after in vitro exposure to phenylephrine is mediated by decreased levels of $\mathrm{G}_{\alpha q}$ and $\mathrm{G}_{\alpha \mathrm{i}}$. J Pharmacol Exp Ther 283: 925-931, 1997.
8. Drake MT, Shenoy SK and Lefkowitz RK: Trafficking of G protein-coupled receptors. Circ Res 99: 570-582, 2006.

9. Keef KD, Hume JR and Zhong J: Regulation of cardiac and smooth muscle $\mathrm{Ca}^{2+}$ channels $\left(\mathrm{Ca}_{\mathrm{v}} 1.2 \mathrm{a}, \mathrm{b}\right)$ by protein kinases. Am J Physiol Cell Physiol 281: C1743-C1756, 2001.

10. Breitwieser GE: G protein-coupled receptor oligomerization: implications for $\mathrm{G}$ protein activation and cell signaling. Circ Res 94: 17-27, 2004.

11. Nauli SM, Williams JM, Akopov SE, Zhang L and Pearce WJ: Developmental changes in ryanodine- and IP3-sensitive $\mathrm{Ca}^{2+}$ pools in ovine basilar artery. Am J Physiol Cell Physiol 281: C1785-C1796, 2001.

12. Valdés JA, Hidalgo J, Galaz JL, Puentes N, Silva M, Jaimovich E and Carrasco MA: NF-B activation by depolarization of skeletal muscle cells depends on ryanodine and IP3 receptor-mediated calcium signals. Am J Physiol Cell Physiol 292: C1960-C1970, 2007.

13. Somlyo AP and Somlyo AV: $\mathrm{Ca}^{2+}$ sensitivity of smooth muscle and non-muscle myosin II: modulated by $\mathrm{G}$ proteins, kinases, and myosin phosphatase. Physiol Rev 83: 1325-1358, 2003.

14. Grzesk G and Szadujkis-Szadurski L: Modulation of the reactivity of $\alpha$-adrenergic receptors by $8 \mathrm{Br}$-cGMP and angiotesin II. Ann Acad Med Bydg 17: 5-10, 2003.

15. Grzesk G and Szadujkis-Szadurski L: Pharmacometric analysis of $\alpha 1$-adrenoceptor function in pretreated with lipopolysaccharides rat tail artery. Pol J Pharmacol 53: 605-613, 2001.

16. Grzesk G, Trajder A, Szadujkis-Szadurska K, Krzyzanowski M and Szadujkis-Szadurski L: Role of $\alpha$-adrenergic receptor reserve in different post-synaptic responses to exogenous agonists in the bisected rat vas deferens. Prog Med Res 3: 13-16, 2005.

17. Furchgott RF and Zawadzki JW: The obligatory role of endothelial cells in relaxation of arterial smooth muscle by acetylocholine. Nature 288: 373-376, 1980.

18. Murad F: The nitric oxide-cyclic GMP signal transduction system for intracellular and intercellular communication. Recent Prog Horm Res 49: 239-248, 1994.

19. Ignarro LJ: Endothelium-derived nitric oxide: actions and properties. FASEB J 3: 31-36, 1989.

20. Xe L, Eu JP, Meissner G and Stamler JS: Activation of the cardiac calcium release channel (ryanodine receptor) by poly-Snitrosylation. Science 279: 234-237, 1998.

21. Sun J, Xin C, Eu JP, Stamler JS and Meissner G: Cysteine-3635 is responsible for skeletal muscle ryanodine receptor modulation by NO. Proc Natl Acad Sci USA 98: 11158-11162, 2001.

22. Lim G, Venetucci L, Eisner DA and Casadei B: Does nitric oxide modulate cardiac ryanodine receptor function? Implications for excitation - contraction coupling. Cardiovasc Res 77: 256-264, 2008.

23. Moncada S, Palmer RM and Higgs EA: Nitric oxide: physiology, pathophysiology, and pharmacology. Pharmacol Rev 43: 109-142, 1991.

24. Bender AT and Beavo JA: Cyclic nucleotide phosphodiesterases: molecular regulation to clinical use. Pharmacol Rev 58: 488-520, 2006.

25. Slupski M, Szadujkis-Szadurski L, Grzesk G, et al: Guanylate cyclase activators influence reactivity of human mesenteric superior arteries retrieved and preserved in the same conditions as transplanted kidneys. Transplant Proc 39: 1350-1353, 2007.

26. Perez-Zoghbi JF, Bai Y and Sanderson MJ: Nitric oxide induces airway smooth muscle cell relaxation by decreasing the frequency of agonist-induced $\mathrm{Ca}^{2+}$ oscillations. J Gen Physiol 135: 247-259, 2010.

27. Ji J, Benishin CG and Pang PKT: Nitric oxide selectively inhibits intracellular $\mathrm{Ca}^{++}$release elicited by inositol trisphosphate but not caffeine in rat vascular smooth muscle. J Pharmacol Exp Ther 285: 16-21, 1998

28. Szadujkis-Szadurski R, Tafil-Klawe M, Szadujkis-Szadurska K, et al: Effect of acetylocholine on reactions induced by 2 contraction agents - angiotensin II and caffeine. Med Biol Sci 24: 53-58, 2010.

29. Szadujkis-Szadurska K, Szadujkis-Szadurski R, SzadujkisSzadurski L, et al: The influence of ischemia and reperfusion injury on the reactivity of arteries induced by angiotensin II and Bay K8644. Med Biol Sci 24: 47-52, 2010.

30. Slupski M, Szadujkis-Szadurska K, Szadujkis-Szadurski R, et al: Nitric oxide and thromboxane A2 modulate pulmonary pressure after ischemia and intestinal reperfusion. Transplant Proc 38: 334-337, 2006. 